\title{
Cytomegalovirus Antibody Elevation in Bipolar Disorder: Relation to Elevated Mood States
}

\author{
A. R. Prossin, ${ }^{1,2}$ R. H. Yolken, ${ }^{3}$ M. Kamali, ${ }^{4}$ M. M. Heitzeg, ${ }^{4}$ \\ J. B. Kaplow, ${ }^{1}$ W. H. Coryell, ${ }^{5}$ and M. G. McInnis ${ }^{4}$ \\ ${ }^{1}$ Department of Psychiatry, University of Texas Health Science Center at Houston, 1941 East Road, No. 2308, Houston, TX 77054, USA \\ ${ }^{2}$ Department of Symptom Research, University of Texas MD Anderson Cancer Center, Houston, TX 77030, USA \\ ${ }^{3}$ Stanley Laboratory of Developmental Neurovirology, Johns Hopkins University Medical Center, Baltimore, MD 21287, USA \\ ${ }^{4}$ Department of Psychiatry, University of Michigan Medical School, Ann Arbor, MI 48109, USA \\ ${ }^{5}$ Department of Psychiatry, University of Iowa School of Medicine, Iowa City, IA 52242, USA
}

Correspondence should be addressed to A. R. Prossin; alan.prossin@uth.tmc.edu

Received 11 September 2014; Accepted 23 October 2014

Academic Editor: João Quevedo

Copyright (c) 2015 A. R. Prossin et al. This is an open access article distributed under the Creative Commons Attribution License, which permits unrestricted use, distribution, and reproduction in any medium, provided the original work is properly cited.

\begin{abstract}
The neurobiology of mood states is complicated by exposure to everyday stressors (e.g., psychosocial, ubiquitous environmental infections like CMV), each fluctuating between latency and reactivation. CMV reactivation induces proinflammatory cytokines (e.g., TNF- $\alpha$ ) associated with induction of neurotoxic metabolites and the presence of mood states in bipolar disorder (BD). Whether CMV reactivation is associated with bipolar diagnoses (trait) or specific mood states is unclear. We investigated $139 \mathrm{BD}$ type I and 99 healthy controls to determine if concentrations of IgG antibodies to Herpesviridae (e.g., CMV, HSV-1, and HSV2) were associated with BD-I diagnosis and specific mood states. We found higher CMV antibody concentration in BD-I than in healthy controls $\left(\mathrm{T}_{234}=3.1, P_{\text {uncorr }}=0.002 ; P_{\text {corr }}=0.006\right)$ but no difference in HSV-1 $(P>0.10)$ or HSV-2 $(P>0.10)$. Compared to euthymic BD-I volunteers, CMV IgG was higher in BD-I volunteers with elevated moods $(P<0.03)$ but not different in depressed moods $(P>0.10)$. While relationships presented between BD-I diagnosis, mood states, and CMV antibodies are encouraging, they are limited by the study's cross sectional nature. Nevertheless, further testing is warranted to replicate findings and determine whether reactivation of CMV infection exacerbates elevated mood states in BD-I.
\end{abstract}

\section{Introduction}

Bipolar disorder $(\mathrm{BD})$ a mood disorder characterized by the presence of elevated, irritable, or mixed mood episodes frequently interspersed with episodes of depression affects approximately $2-3 \%$ of the population [1-3]. Despite substantial individual and societal impact, knowledge of the biological processes underlying and driving mood states in BD is limited. Revealing associations between biological factors and both mood traits and states will set a trajectory for understanding the pathophysiology of moods and in developing novel, more efficacious intervention strategies in BD.

Ubiquitous environmental infections (e.g., Herpesviridae including cytomegalovirus; CMV) and associated human immune responses fluctuate between latency and reactivation in humans, potentially triggered by psychosocial stressors [46]. Viruses may facilitate exacerbation of psychiatric disease pathology through various mechanisms, including induction of inflammatory factors (e.g., TNF- $\alpha$, IL-6, etc.) [7] or via direct interactions with specific illness susceptibility genes. A recent preliminary fMRI study of pediatric bipolar disorder may suggest a mechanism whereby alterations in TNF- $\alpha$ related processes could impact some of the symptoms in BD-I. In this study, Barzman et al. identified correlations between 11 TNF- $\alpha$ related gene expressions and activation within the amygdala or anterior cingulate cortex during the affective Posner task [8]. Evidence from recent studies in BD also shows that TNF- $\alpha$ is higher in BD volunteers compared to healthy control volunteers $[9,10]$. Further, as outlined in 
a review by Brietzke et al., existing evidence suggests that TNF- $\alpha$ is higher in the midst mood episodes in BD volunteers as compared to healthy control volunteers $[10,11]$.

Amongst the potential viral candidates, the herpesvirus family has received the most attention. Certain Herpesviridae (e.g., HSV-1) have been associated with clinical features of BD [12], but to date, no studies have determined whether CMV is associated with the presence of either mania or depression in BD. However, evidence from volunteers with schizophrenia, a psychiatric illness sharing certain clinical and biological features with BD (see review by Prossin and colleagues) [13], suggests that Cytomegalovirus (CMV) may interact with certain high risk genetic loci to precipitate schizophrenia illness [14-18].

Following the diathesis-stress model of disease [19], exposure to environmental stressors (psychosocial, behavioral, and biological) could potentially increase risk for psychiatric illness, particularly in individuals at high genetic risk for that illness [20, 21]. However, while knowledge of behavioral phenotype in BD has grown [22], facilitating development of more efficacious behavioral interventions (e.g., interpersonal and social rhythm therapy) [23], the biologically based environmental factors contributing to $\mathrm{BD}$ remain elusive. Discovery of such factors will facilitate development of novel, personalized, immune-based treatment strategies in this debilitating, life-threatening illness. Here, in cross sectional analyses of volunteers enrolled in a longitudinal study of bipolar disorder, we test our hypotheses that BD volunteers have higher Herpesviridae (e.g., CMV, HSV-1, and HSV-2) IgG concentrations compared to healthy control volunteers and that concentration of these antibodies is associated with common behavioral phenotypes in $\mathrm{BD}$, elevated and/or depressed mood state(s).

\section{Materials and Methods}

The study was approved by the University of Michigan Investigational Review Board. Written informed consent was obtained from all study participants.

We randomly selected 238 volunteers between 18 and 65 years of age from the Prechter Bipolar Longitudinal Study (139 with BD-I and 99 healthy controls). Volunteers either met DSM IV [24] criteria for BD-I (at least one prior primary manic and/or mixed episode) (with or without comorbid substance use, other psychiatric disorders) or were healthy controls, without mental health diagnoses (on either axis I or axis II) [24]. DSM IV [24] diagnoses were assessed using the Diagnostic Inventory for Genetic Studies (DIGS) [25]. Following the diagnostic interview, all volunteers, provided they do not withdraw consent, remain in the Prechter Bipolar Longitudinal Study regardless of the diagnosis(es) determined. For the current study, we selected 238 volunteers who were actively participating in the Prechter Longitudinal Study. Prechter Bipolar Longitudinal Study volunteers routinely return to the research center for follow-up assessments, including longitudinal diagnostic confirmation and mood assessments. Upon their return to the center, subjects were chosen for the current study based on their availability/consent for blood sampling on a first come first serve basis and within a limited time frame. All volunteers for the current study, including both healthy control volunteers and BD-I volunteers, were actively participating in the Prechter Bipolar Longitudinal Study.

Additional mood measures including Hamilton Depression Rating Scale (HDRS) [26] and Young Mania Rating Scale (YMRS) [27] were completed during assessments, consistent with time of blood sampling. The YMRS and HDRS were dichotomized into clinically elevated mood (YMRS > 7), clinically depressed mood (HDRS $>7$ ), and clinically mixed mood (YMRS $>7$ and HDRS $>7$ ).

Overall, the mean age of volunteers was $36 \pm 14$ years of age. Study entry was not constrained by either body mass index (BMI) or sex. Based on evidence implicating their potential impact on immune functioning these variables were entered into analyses to test for individual effects of age, sex, or BMI on CMV IgG. Diagnostic breakdown of anthropometric and sociodemographic variables is included in Table 1. Whether or not patients were treated with psychotropic medications (i.e., lithium, lamotrigine, valproate, carbamazepine, atypical antipsychotic, or antidepressant medication) was included in analyses as a dichotomous variable, medication usage.

Whole venous blood was sampled following completion of psychiatric assessments at $1 \mathrm{PM}( \pm 1$ hour). Samples were centrifuged for 15 minutes at $4750 \mathrm{rpm}$ and plasma was extracted and stored at $-80^{\circ} \mathrm{C}$. Serology assessments were performed at the Stanley Neurovirology Laboratory (Johns Hopkins University School of Medicine, Baltimore, MD). CMV IgG antibody concentrations were expressed quantitatively as both continuous (e.g., concentration) and dichotomous (e.g., seropositive, seronegative) measures, each derived via comparisons to standard samples run concurrently in each assay, as previously described [28]. Similar processes were completed for quantification of Herpes Simplex Virus Type I (HSV-1) and Herpes Simplex Virus Type 2 (HSV2).

\section{Data Analytic Plan}

SPSS Statistics software version 21 (IBM Inc., Chicago, IL) was used to plot the data, rule out the presence of outliers, and perform additional statistical analyses. Medication usage (described above) was used to rule out overt effects of psychotropic medications on CMV IgG. Planned analyses included usage of independent samples T-tests to detect diagnostic differences in viral antibody concentrations (CMV, HSV-1, and HSV-2). Subsequent analyses used separate independent samples T-tests to identify whether CMV antibody concentrations were higher in BD-I volunteers in the midst of a mood episode (i.e., with or without a depressed mood episode, with or without a manic mood episode) while controlling for covariates (age, sex, race, and $\mathrm{BMI}$ ). Subsequently, we used the Pearson chi-squared test, to show that CMV antibody status was similar in BD-I groups with and without current psychotropic treatment. Separate Spearman correlation analyses (and independent samples Ttesting) tested for the presence of linear relationships between CMV antibody concentrations and either age, BMI, sex, or medication treatment, all factors potentially associated with 
TABLE 1: Here we provide demographic and anthropometric information on study volunteers.

\begin{tabular}{lccccccccccc}
\hline & Age & \multicolumn{2}{c}{ Sex } & & \multicolumn{3}{c}{ Race } & \multicolumn{3}{c}{$\begin{array}{c}\text { Body mass index } \\
\text { (BMI) }\end{array}$} \\
Diagnosis & $\begin{array}{c}\text { Mean } \pm \text { SD } \\
(n=237)\end{array}$ & $\begin{array}{c}\text { Male } \\
(n=101)\end{array}$ & $\begin{array}{c}\text { Female } \\
(n=137)\end{array}$ & $\begin{array}{c}\text { American } \\
\text { Alaskan } \\
\text { Native }\end{array}$ & $\begin{array}{c}\text { Asian } \\
\text { Black } \\
\text { African } \\
\text { American }\end{array}$ & $\begin{array}{c}\text { White } \\
\text { Caucasian }\end{array}$ & $\begin{array}{c}\text { More } \\
\text { than one } \\
\text { race }\end{array}$ & $\begin{array}{c}\text { Unknown } \\
\text { Mean } \pm \text { SD } \\
(n=130)\end{array}$ \\
\hline Bipolar disorder & $39 \pm 13$ & $37 \%$ & $63 \%$ & $0.7 \%$ & $2.9 \%$ & $3.6 \%$ & $87.1 \%$ & $4.3 \%$ & $1.4 \%$ & $29 \pm 8$ \\
type I & $(n=138)$ & $(n=52)$ & $(n=87)$ & $(n=1)$ & $(n=4)$ & $(n=5)$ & $(n=121)$ & $(n=6)$ & $(n=2)$ & $(n=132)$ \\
Healthy control & $32 \pm 14$ & $49 \%$ & $51 \%$ & $0 \%$ & $12.1 \%$ & $15.2 \%$ & $68.7 \%$ & $4.0 \%$ & $0 \%$ & $26 \pm 6$ \\
$(n=99)$ & $(n=49)$ & $(n=50)$ & $(n=0)$ & $(n=12)$ & $(n=15)$ & $(n=68)$ & $(n=4)$ & $(n=0)$ & $(n=98)$ \\
\hline
\end{tabular}

Results are presented as mean \pm standard deviation for body mass index (BMI) and as percentages for other variables within each diagnostic group. These measures include age, sex, race, and body mass index.

TABLE 2: Here we provide clinical information on study volunteers.

\begin{tabular}{|c|c|c|c|c|c|c|c|c|}
\hline \multirow[b]{2}{*}{ Diagnosis } & \multirow{2}{*}{$\begin{array}{c}\text { HDRS } \\
\text { Mean } \pm \text { SD } \\
(n=235)\end{array}$} & \multirow{2}{*}{$\begin{array}{c}\text { YMRS } \\
\text { Mean } \pm \text { SD } \\
(n=230)\end{array}$} & \multicolumn{6}{|c|}{ Medication use } \\
\hline & & & AAP's & Antidepressant & Lithium & Valproate & Lamotrigine & Carbamazepine \\
\hline Bipolar disorder type I & $\begin{array}{l}8.1 \pm 7.6 \\
(n=137) \\
\end{array}$ & $\begin{array}{l}3.6 \pm 5.6 \\
(n=134) \\
\end{array}$ & $45 \%$ & $50 \%$ & $36 \%$ & $20 \%$ & $24 \%$ & $5 \%$ \\
\hline Healthy control & $\begin{array}{r}0.7 \pm 1.3 \\
(n=98)\end{array}$ & $\begin{array}{r}0.1 \pm 0.3 \\
(n=96)\end{array}$ & $0 \%$ & $0 \%$ & $0 \%$ & $0 \%$ & $0 \%$ & $0 \%$ \\
\hline
\end{tabular}

Results are presented as mean \pm standard deviation (and percentage of volunteers using a particular medication) within each diagnostic group. These measures include Hamilton 17-item Depression Rating Scale (HDRS), Young Mania Rating Scale (YMRS), and medication use including AAP's (atypical antipsychotics), antidepressants, lithium, valproate, lamotrigine, and carbamazepine.

variation in immune activation, to determine whether these factors were likely confounding our results. Data shown are corrected for multiple comparisons where indicated by " $P_{\text {corr }}$ " using the Bonferroni technique [29] (uncorrected $P$-values are simply stated as " $P=$ "). Statistical significance for all analyses was set at $P=0.05$.

\section{Results}

In total, plasma samples from 238 study volunteers were assayed for CMV, HSV-1, and HSV-2 antibodies. Of these 238 volunteers, 139 had a diagnosis of BD-I and 99 were healthy controls. Of the 139 BD-I volunteers, sixty-seven BD-I individuals (48\%) exhibited evidence of clinically significant mood symptoms (e.g., depressed, elevated, and mixed). Sixtyone BD-I individuals (44\%) had clinically significant depression, 22 BD-I individuals (16\%) had clinically significant mood elevation, and 13 BD-I individuals (9\%) had symptoms consistent with that of a mixed mood state. Mean values of behavioral measures of interest (e.g., YMRS, HDRS) are presented for each diagnostic study group (e.g., BD-I, healthy controls) in Table 2.

Using independent samples T-testing, we found that volunteers with a diagnosis of BD-I have significantly greater CMV IgG concentrations $\left(\mathrm{T}_{234}=3.1 ; P=0.002 ; P_{\text {corr }}=\right.$ 0.006 ; mean difference $1.0 \pm 0.3$ ) as compared to healthy control volunteers. However, no diagnostic differences were identified with regard to HSV-1 $\operatorname{IgG}\left(\mathrm{T}_{236}=0.15 ; P=0.89\right)$ and HSV-2 IgG $\left(\mathrm{T}_{236}=0.14 ; P=0.89\right)$. Graphical depiction of diagnostic differences in viral antibody concentrations is illustrated in Figure 1; statistical comparisons involving CMV IgG are outlined in Table 3.
Separate independent samples T-tests found that CMV IgG concentrations were higher in those BD-I volunteers in the midst of a clinically elevated mood state $\left(\mathrm{T}_{132}=2.2\right.$; $P=0.03$; mean difference $1.3 \pm 0.6$ ) but not significantly different in those BD-I volunteers in a clinically depressed mood state $(P>0.10)$ as compared to those study volunteers not in a clinically elevated mood state or clinically depressed mood state, respectively.

Results from individual Spearman correlational testing showed that CMV antibody concentrations were not significantly correlated with either body mass index $(P>$ $0.10)$ or age $(P>0.10)$ in BD-I volunteers. Additionally in BD-I volunteers, using separate independent samples Ttests, we found that (1) CMV antibody concentrations were not significantly different in females as compared to males $(P>0.10)$ and $(2) \mathrm{CMV}$ antibody concentrations were not significantly different in volunteers who were being treated with psychotropic medications as compared to volunteers not receiving psychotropic medication treatment $(P>0.10)$.

\section{Discussion}

This study identified an association between concentrations of plasma CMV IgG antibodies and a diagnosis of BD-I, with BD-I individuals having significantly higher CMV concentrations than healthy control volunteers. Further, chi-squared testing described in Table 3 showed that CMV IgG seropositivity was associated with greater than 5 times increased likelihood of having a diagnosis of BD-I (Table 3). This finding aligns with previous findings of CMV IgG seropositivity in psychiatric disorders, specifically schizophrenia [14-18], 
TABLE 3: Here we provide CMV IgG concentrations (reported as mean \pm standard deviation in column 2) for each diagnosis, BD-I and healthy controls.

\begin{tabular}{|c|c|c|c|c|c|}
\hline \multirow{2}{*}{ Diagnosis } & \multirow{2}{*}{$\begin{array}{l}\text { CMV IgG concentrations } \\
\text { Mean } \pm \text { SD }\end{array}$} & \multirow{2}{*}{$\begin{array}{c}\text { Diagnostic comparison of CMV } \\
\text { Antibody concentrations }\end{array}$} & \multicolumn{2}{|c|}{ CMV IgG seropositivity } & \multirow{2}{*}{$\begin{array}{c}\text { Pearson chi-square } \\
\text { Testing }\end{array}$} \\
\hline & & & Seronegative & Seropositive & \\
\hline $\begin{array}{l}\text { Healthy control } \\
\text { volunteers }\end{array}$ & $2.1 \pm 2.1(n=99)$ & \multirow{2}{*}{$\begin{array}{l}\mathrm{T}_{234}=3.1 \\
P=0.002\end{array}$} & $n=59$ & $n=40$ & \multirow{2}{*}{$\begin{array}{c}\text { Likelihood ratio }=5.2 \\
P=0.02\end{array}$} \\
\hline $\begin{array}{l}\text { Bipolar disorder } \\
\text { type I }\end{array}$ & $3.0 \pm 2.7(n=139)$ & & $n=62$ & $n=77$ & \\
\hline
\end{tabular}

Results of independent samples T-testing are reported in column 3. We identify significantly greater concentration of CMV IgG in BD-I volunteers as compared to healthy control volunteers $\left(\mathrm{T}_{234}=3.1, P_{\text {uncorr }}=0.002\right.$, and $\left.P_{\text {corr }}=0.006\right)$. Chi-squared testing confirmed that CMV IgG seropositivity status was associated with 5.2 times greater likelihood of the presence of a diagnosis of BD-I $(P=0.02)$. Neither HSV-1 nor HSV-2 differed significantly between the BD-I and healthy control groups.

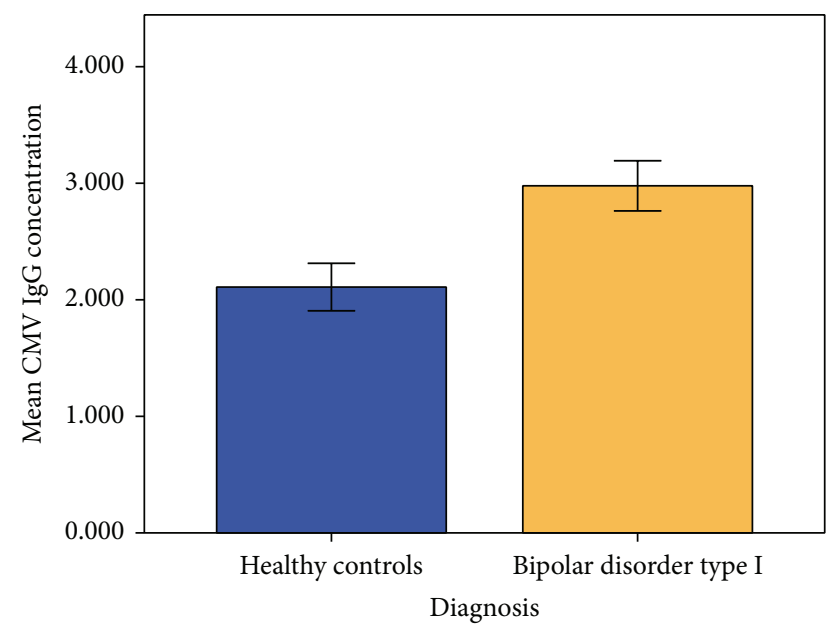

Error bars: $\pm 1 \mathrm{SE}$

Figure 1: Graphical depiction of diagnostic differences in Cytomegalovirus (CMV) antibody concentrations. Standardized mean antibody (IgG) concentrations are depicted on the vertical, $y$ axis and diagnosis on the horizontal $x$-axis. CMV IgG concentration was higher in BD-I volunteers (shown in maize color) as compared to healthy control volunteers (shown in blue color) $\left(\mathrm{T}_{234}=3.1\right.$; $\left.P_{\text {uncorr }}=0.002 ; P_{\text {corr }}=0.006\right)$. No diagnostic differences were identified with regard to HSV-1 $\operatorname{IgG}\left(\mathrm{T}_{236}=0.15 ; P=0.89\right)$ and HSV-2 IgG $\left(\mathrm{T}_{236}=0.14 ; P=0.89\right)$. Error bars represent \pm 1 standard error.

and supports the hypothesis that exposure to environmental/infectious factors like viruses may contribute to the pathophysiology of BD-I. While recent evidence showed that passage of maternal CMV antibodies to the neonate in expecting mothers was not shown to pose significant risk of BD-I in the neonate [30], results we present of associations between CMV antibody concentrations, diagnosis of BD-I, and elevated mood state warrant further investigation and clarification on questions of causality. Approximately $50 \%$ of Americans are seropositive for CMV [31]. Initial exposure to infectious agents like CMV induces an immune response [32], memory of the infection persisting in the form of CMV IgG antibodies. Subsequently, CMV persists in a latent state in immature cells [33]. Exposure to psychosocial stress can potentially downregulate cellular immune responsivity [34-36] reactivating otherwise latent herpesviruses (e.g., CMV) [37], inducing herpesvirus (e.g., CMV) antibodies [5]. Taken together with the findings we report this evidence suggests that treatment of ubiquitous, asymptomatic herpesvirus infections or targeting their downstream counterparts (e.g., TNF- $\alpha$ ) could potentially impact the BD-I illness. However, much further testing on expanded, longitudinal BD-I samples is required to test these hypotheses. Separate evidence does show that elevation of soluble CMV antigens and CMV antibody concentrations is associated with a shift towards $\mathrm{CD}^{+} \mathrm{T}$-cell production [32] and subsequent induction of $\mathrm{CD}^{+}$derived proinflammatory cytokines (e.g., TNF- $\alpha$, IL- 6 , and IFN- $\gamma$ ) $[7,38,39]$. Further, enhanced immune activation involving elevated concentrations of these cytokines has been identified in $\mathrm{BD}$ volunteers [40] and phasic variation in common clinical features of BD (e.g., depression, mania, suicidality, etc.) has also been associated with particular inflammatory cytokine profiles [41]. Induction of TNF- $\alpha$ has been shown to modulate neurotransmitter metabolism via activation of indoleamine 2,3-dioxygenase (IDO), subsequently reducing neurotransmitter precursors (i.e., tryptophan), and shifting the balance towards production of potentially neurotoxic metabolites (i.e., hydroxykynurenine) [42-45]. The resulting alteration of neurotransmitter metabolism is believed to directly impact central processing of emotionally salient and stressful events, resulting in altered behavioral response to stress [46-51].

In summary, these results augment accumulating evidence suggesting that exposure to Herpesviridae in general (and CMV in particular), its subsequent acquired immune response, and the impact of psychological stressors on immune reactivation may pose a risk of BD-I, potentially via an impact on development or exacerbation of elevated mood states. However, the cross sectional nature of analyses involving CMV in our study limits the extent that causal inferences can be drawn. Potentially, the means by which episodic inflammatory alterations contribute to episodic clinical features in BD could be ascribed to this model but further research in this area is required to discern the exact mechanisms underlying CMV's relationship to clinical mood states in BD-I. Additionally, while we found no significant differences in CMV antibody concentrations when comparing BD-1 volunteers receiving pharmacotherapy against those not receiving pharmacotherapy, it remains as a possibility 
that interindividual variation in specific psychiatric medication used (and/or specific dosage prescribed) could be confounding the results. Future studies that include designs with an expanded population of BD-I volunteers will be better positioned to test for the presence of medication specific effects on CMV antibody concentrations.

\section{Conflict of Interests}

The authors declare that there is no conflict of interests regarding the publication of this paper.

\section{Acknowledgments}

The authors acknowledge Steven S. Zalcman, Ph.D. degree holder (deceased), Christine Brucksh, Gloria Harrington, Kenneth Ng, B.S. degree holder, and Kristen Wiese, Pharm.D degree holder.

\section{References}

[1] K. R. Merikangas, H. S. Akiskal, J. Angst et al., "Lifetime and 12month prevalence of bipolar spectrum disorder in the national comorbidity survey replication," Archives of General Psychiatry, vol. 64, no. 5, pp. 543-552, 2007.

[2] K. R. Merikangas, R. Jin, J.-P. He et al., "Prevalence and correlates of bipolar spectrum disorder in the world mental health survey initiative," Archives of General Psychiatry, vol. 68, no. 3, pp. 241-251, 2011.

[3] A. Schmitt, B. Malchow, A. Hasan, and P. Falkai, "The impact of environmental factors in severe psychiatric disorders," Frontiers in Neuroscience, no. 8, article 19, 2014.

[4] S. E. Keller, J. M. Weiss, S. J. Schleifer, N. E. Miller, and M. Stein, "Stress-induced suppression of immunity in adrenalectomized rats," Science, vol. 221, no. 4617, pp. 1301-1304, 1983.

[5] S. Prösch, C. E. C. Wendt, P. Reinke et al., "A novel link between stress and human cytomegalovirus (HCMV) infection: sympathetic hyperactivity stimulates HCMV activation," Virology, vol. 272, no. 2, pp. 357-365, 2000.

[6] S. J. Schleifer, S. E. Keller, M. Camerino, J. C. Thornton, and M. Stein, "Suppression of lymphocyte stimulation following bereavement," The Journal of the American Medical Association, vol. 250, no. 3, pp. 374-377, 1983.

[7] J. Jelinek, I. Adkins, Z. Mikulkova et al., "In vitro activation of CMV-specific human CD $8^{+} \mathrm{T}$ cells by adenylate cyclase toxoids delivering pp65 epitopes," Bone Marrow Transplantation, vol. 47, no. 2, pp. 243-250, 2012.

[8] D. Barzman, J. Eliassen, R. McNamara et al., "Correlations of inflammatory gene pathways, corticolimbic functional activities, and aggression in pediatric bipolar disorder: a preliminary study," Psychiatry Research, vol. 224, no. 2, pp. 107-111, 2014.

[9] I. G. Barbosa, C. R. C. Nogueira, N. P. Rocha et al., "Altered intracellular signaling cascades in peripheral blood mononuclear cells from BD patients," Journal of Psychiatric Research, vol. 47, no. 12, pp. 1949-1954, 2013.

[10] S. M. O’Brien, P. Scully, L. V. Scott, and T. G. Dinan, "Cytokine profiles in bipolar affective disorder: focus on acutely ill patients," Journal of Affective Disorders, vol. 90, no. 2-3, pp. 263$267,2006$.
[11] E. Brietzke and F. Kapczinski, "TNF- $\alpha$ as a molecular target in bipolar disorder," Progress in Neuro-Psychopharmacology and Biological Psychiatry, vol. 32, no. 6, pp. 1355-1361, 2008.

[12] F. B. Dickerson, J. J. Boronow, C. Stallings et al., "Infection with herpes simplex virus type 1 is associated with cognitive deficits in bipolar disorder," Biological Psychiatry, vol. 55, no. 6, pp. 588593, 2004.

[13] M. M. Prossin A, A. Anand, M. Heitzeg, and J.-K. Zubieta, "Tackling the Kraepelinian Dichotomy: a neuroimaging review," Psychiatric Annals, vol. 40, pp. 162-167, 2010.

[14] J. J. Kim, B. H. Shirts, M. Dayal et al., "Are exposure to cytomegalovirus and genetic variation on chromosome $6 \mathrm{p}$ joint risk factors for schizophrenia?" Annals of Medicine, vol. 39, no. 2, pp. 145-153, 2007.

[15] F. M. Leweke, C. W. Gerth, D. Koethe et al., "Antibodies to infectious agents in individuals with recent onset schizophrenia," European Archives of Psychiatry and Clinical Neuroscience, vol. 254, no. 1, pp. 4-8, 2004.

[16] B. H. Shirts, J. J. Kim, S. Reich et al., "Polymorphisms in MICB are associated with human herpes virus seropositivity and schizophrenia risk," Schizophrenia Research, vol. 94, no. 1-3, pp. 342-353, 2007.

[17] B. H. Shirts, K. M. Prasad, M. F. Pogue-Geile, F. Dickerson, R. H. Yolken, and V. L. Nimgaonkar, "Antibodies to cytomegalovirus and Herpes Simplex Virus 1 associated with cognitive function in schizophrenia," Schizophrenia Research, vol. 106, no. 2-3, pp. 268-274, 2008.

[18] E. F. Torrey, M. F. Leweke, M. J. Schwarz et al., "Cytomegalovirus and schizophrenia," CNS Drugs, vol. 20, no. 11, pp. 879-885, 2006.

[19] R. S. Lazarus, "From psychological stress to the emotions: a history of changing outlooks," Annual Review of Psychology, vol. 44, no. 1, pp. 1-21, 1993.

[20] A. Caspi and T. E. Moffitt, "Gene-environment interactions in psychiatry: joining forces with neuroscience," Nature Reviews Neuroscience, vol. 7, no. 7, pp. 583-590, 2006.

[21] T. E. Moffitt, A. Caspi, and M. Rutter, "Strategy for investigating interactions between measured genes and measured environments," Archives of General Psychiatry, vol. 62, no. 5, pp. 473481, 2005.

[22] C. L. Ehlers, E. Frank, and D. J. Kupfer, "Social zeitgebers and biological rhythms: a unified approach to understanding the etiology of depression," Archives of General Psychiatry, vol. 45, no. 10 , pp. 948-952, 1988.

[23] H. A. Swartz, E. Frank, K. O’Toole et al., "Implementing interpersonal and social rhythm therapy for mood disorders across a continuum of care," Psychiatric Services, vol. 62, no. 11, pp. 1377-1380, 2011.

[24] D.-I. Apatfo, Diagnostic and Statistical Manual of Mental Disorders, text revision, New York, NY, USA, 4th edition, 2000.

[25] J. I. Nurnberger Jr., M. C. Blehar, C. A. Kaufmann et al., "Diagnostic interview for genetic studies: rationale, unique features, and training," Archives of General Psychiatry, vol. 51, no. 11, pp. 849-859, 1994.

[26] M. Hamilton, "Development of a rating scale for primary depressive illness," British Journal of Social and Clinical Psychology, vol. 6, no. 4, pp. 278-296, 1967.

[27] R. C. Young, J. T. Biggs, V. E. Ziegler, and D. A. Meyer, "A rating scale for mania: reliability, validity and sensitivity", The British Journal of Psychiatry, vol. 133, no. 11, pp. 429-435, 1978. 
[28] F. B. Dickerson, J. J. Boronow, C. R. Stallings, A. E. Origoni, and R. H. Yolken, "Reduction of symptoms by valacyclovir in cytomegalovirus-seropositive individuals with schizophrenia," The American Journal of Psychiatry, vol. 160, no. 12, pp. 22342236, 2003.

[29] C. E. Bonferroni, “Teoria statistica delle classi e calcolo delle probabilità," Pubblicazioni del R Istituto Superiore di Scienze Economiche e Commerciali di Firenze, vol. 8, pp. 3-62, 1936.

[30] P. B. Mortensen, C. B. Pedersen, J. J. Mcgrath et al., "Neonatal antibodies to infectious agents and risk of bipolar disorder: a population-based case-control study," Bipolar Disorders, vol. 13, no. 7-8, pp. 624-629, 2011.

[31] S. L. Bate, S. C. Dollard, and M. J. Cannon, "Cytomegalovirus seroprevalence in the United States: the national health and nutrition examination surveys, 1988-2004," Clinical Infectious Diseases, vol. 50, no. 11, pp. 1439-1447, 2010.

[32] P. Moss and N. Khan, "CD8 ${ }^{+}$T-cell immunity to cytomegalovirus," Human Immunology, vol. 65, no. 5, pp. 456-464, 2004.

[33] T. Crough and R. Khanna, "Immimobiology of human cytomegalovirus: from bench to bedside," Clinical Microbiology Reviews, vol. 22, no. 1, pp. 76-98, 2009.

[34] M. T. Caserta, T. G. O'Connor, P. A. Wyman et al., "The associations between psychosocial stress and the frequency of illness, and innate and adaptive immune function in children," Brain, Behavior, and Immunity, vol. 22, no. 6, pp. 933-940, 2008.

[35] R. Glaser and J. Kiecolt-Glaser, "How stress damages immune system and health," Discovery Medicine, vol. 5, no. 26, pp. 165$169,2005$.

[36] R. Glaser, B. Rabin, M. Chesney, S. Cohen, and B. Natelson, "Stress-induced immunomodulation: implications for infectious diseases?" The Journal of the American Medical Association, vol. 281, no. 24, pp. 2268-2270, 1999.

[37] R. Glaser, S. B. Friedman, J. Smyth et al., "The differential impact of training stress and final examination stress on herpesvirus latency at the United States Military Academy at West Point," Brain, Behavior, and Immunity, vol. 13, no. 3, pp. 240-251, 1999.

[38] Y. J. Tang-Feldman, G. R. Lochhead, S. R. Lochhead, C. Yu, and C. Pomeroy, "Interleukin-10 repletion suppresses proinflammatory cytokines and decreases liver pathology without altering viral replication in murine cytomegalovirus (MCMV)infected IL-10 knockout mice," Inflammation Research, vol. 60, no. 3, pp. 233-243, 2011.

[39] S. Varani, G. Rossini, A. Mastroianni et al., "High TNF-alpha and IL-8 levels predict low blood dendritic cell counts in primary cytomegalovirus infection," Journal of Clinical Virology, vol. 53, no. 4, pp. 360-363, 2012.

[40] S. Hope, I. Melle, P. Aukrust et al., "Similar immune profile in bipolar disorder and schizophrenia: selective increase in soluble tumor necrosis factor receptor I and von Willebrand factor," Bipolar Disorders, vol. 11, no. 7, pp. 726-734, 2009.

[41] A. Ortiz-Domínguez, M. E. Hernández, C. Berlanga et al., "Immune variations in bipolar disorder: phasic differences," Bipolar Disorders, vol. 9, no. 6, pp. 596-602, 2007.

[42] A. H. Miller, "Mechanisms of cytokine-induced behavioral changes: psychoneuroimmunology at the translational interface," Brain, Behavior, and Immunity, vol. 23, no. 2, pp. 149-158, 2009.

[43] A. H. Miller, V. Maletic, and C. L. Raison, "Inflammation and its discontents: the role of cytokines in the pathophysiology of major depression," Biological Psychiatry, vol. 65, no. 9, pp. 732741, 2009.
[44] S. Okuda, N. Nishiyama, H. Saito, and H. Katsuki, "Hydrogen peroxide-mediated neuronal cell death induced by an endogenous neurotoxin, 3-hydroxykynurenine," Proceedings of the National Academy of Sciences of the United States of America, vol. 93, no. 22, pp. 12553-12558, 1996.

[45] S. Okuda, N. Nishiyama, H. Saito, and H. Katsuki, "3Hydroxykynurenine, an endogenous oxidative stress generator, causes neuronal cell death with apoptotic features and region selectivity," Journal of Neurochemistry, vol. 70, no. 1, pp. 299307, 1998.

[46] L. Brydon, N. A. Harrison, C. Walker, A. Steptoe, and H. D. Critchley, "Peripheral inflammation is associated with altered substantia nigra activity and psychomotor slowing in humans," Biological Psychiatry, vol. 63, no. 11, pp. 1022-1029, 2008.

[47] L. Capuron, G. Pagnoni, M. Demetrashvili et al., "Anterior cingulate activation and error processing during interferonalpha treatment," Biological Psychiatry, vol. 58, no. 3, pp. 190196, 2005.

[48] N. A. Harrison, L. Brydon, C. Walker, M. A. Gray, A. Steptoe, and H. D. Critchley, "Inflammation causes mood changes through alterations in subgenual cingulate activity and mesolimbic connectivity," Biological Psychiatry, vol. 66, no. 5, pp. 407-414, 2009.

[49] N. A. Harrison, L. Brydon, C. Walker et al., "Neural origins of human sickness in interoceptive responses to inflammation," Biological Psychiatry, vol. 66, no. 5, pp. 415-422, 2009.

[50] A. R. Prossin, A. E. Koch, P. L. Campbell, M. G. McInnis, S. S. Zalcman, and J.-K. Zubieta, "Association of plasma interleukin18 levels with emotion regulation and $\mu$-opioid neurotransmitter function in major depression and healthy volunteers," Biological Psychiatry, vol. 69, no. 8, pp. 808-812, 2011.

[51] C. L. Raison, R. Dantzer, K. W. Kelley et al., "CSF concentrations of brain tryptophan and kynurenines during immune stimulation with IFN- $\alpha$ : relationship to CNS immune responses and depression," Molecular Psychiatry, vol. 15, no. 4, pp. 393-403, 2010. 

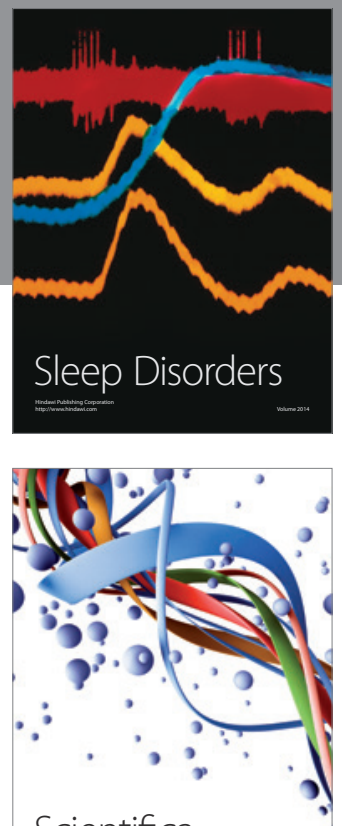

Scientifica
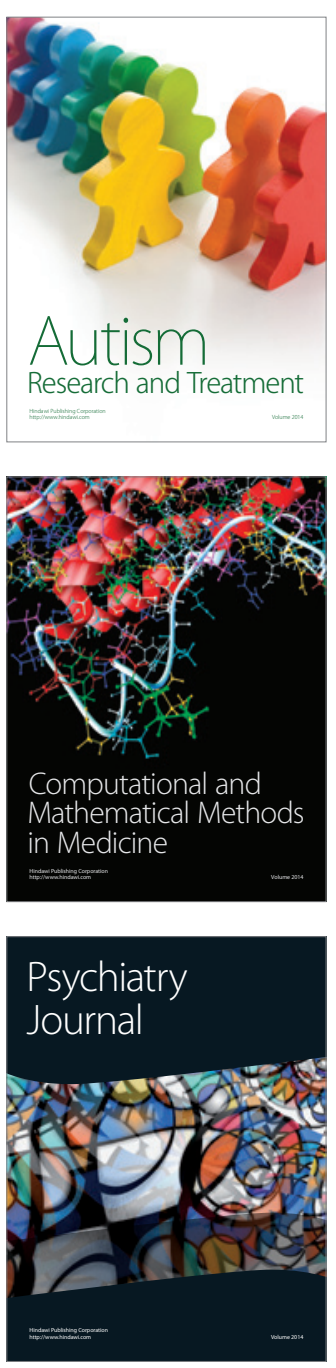
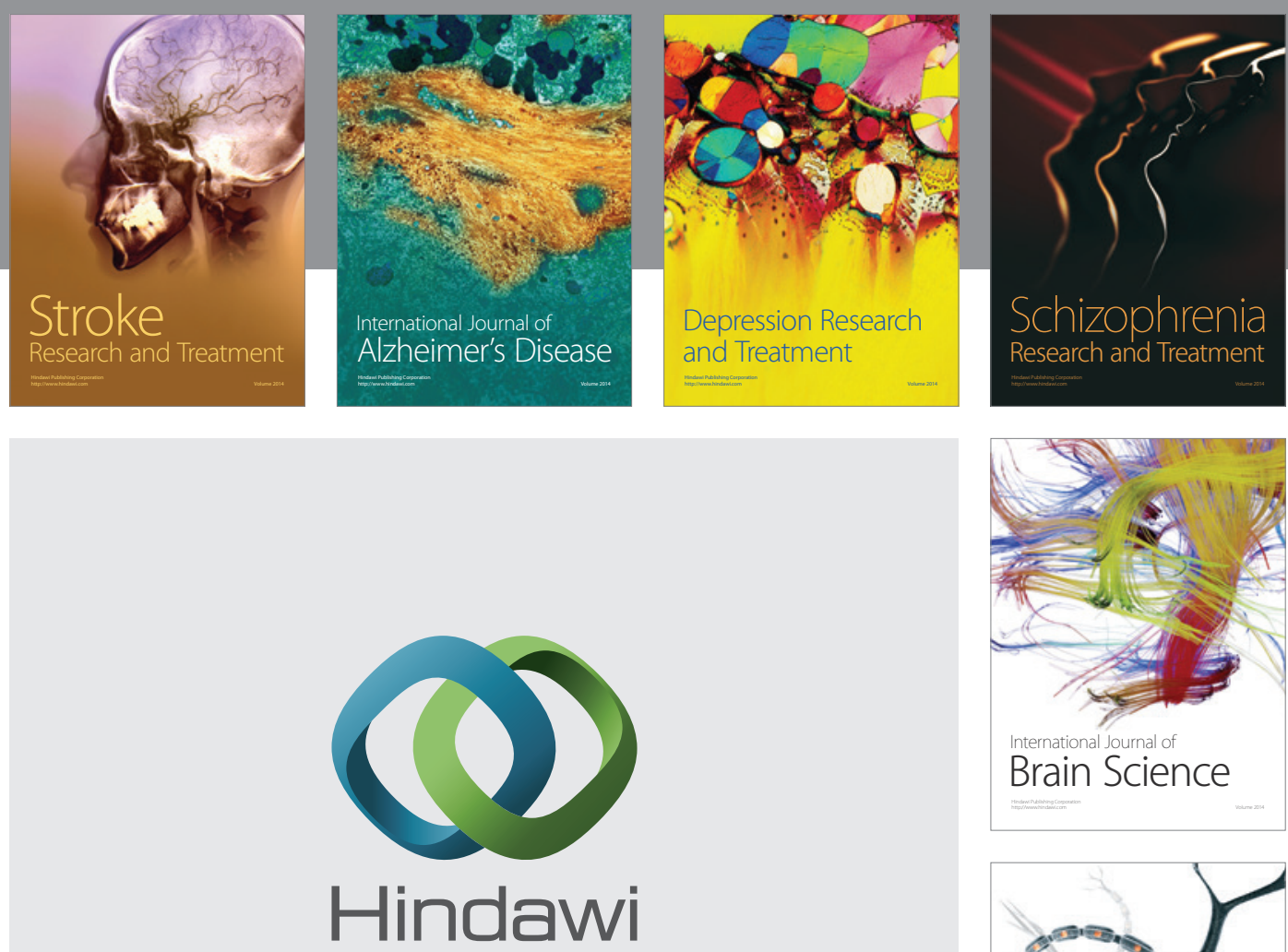

Submit your manuscripts at

http://www.hindawi.com
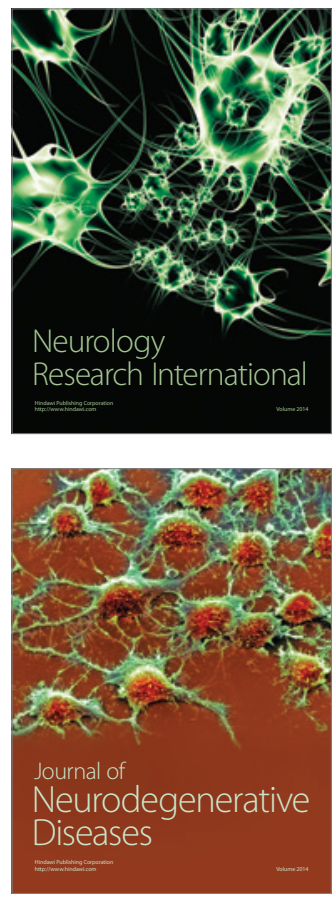

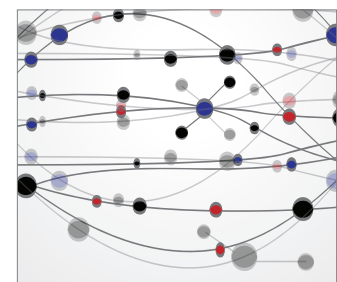

The Scientific World Journal
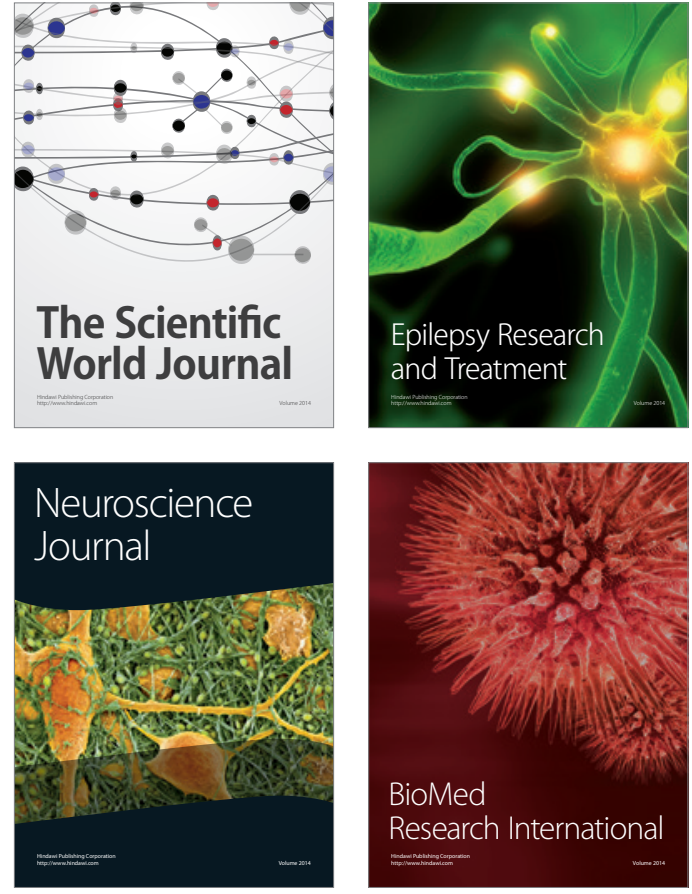

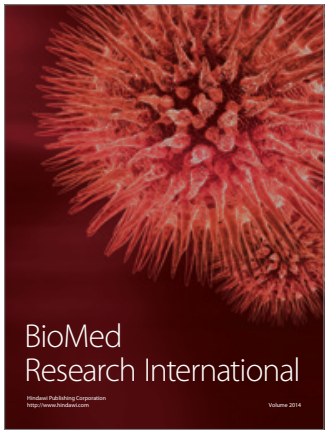

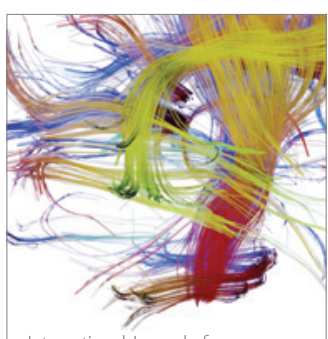

Brain Science

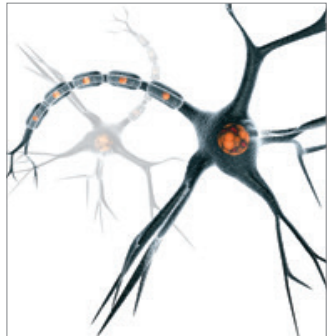

Neural Plasticity
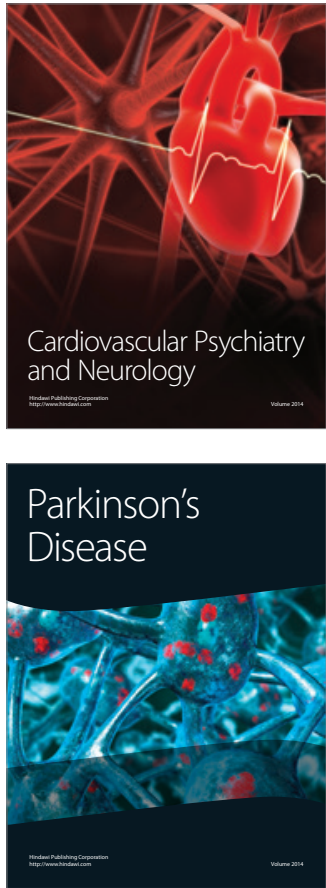